\title{
Grammarly: An Online EFL Writing Companion
}

\author{
${ }^{1}$ N.M.F. Amin Mubarok, ${ }^{2}$ Ahmad Syafi'i \\ 1nmfam.id@email.com \\ ${ }^{1}$ Prodi Pendidikan Bahasa Inggris STKIP Al Hikmah Surabaya \\ 2ahmadsyafii20@gmail.com \\ ${ }^{2}$ Prodi Pendidikan Bahasa Inggris STKIP Al Hikmah Surabaya
}

\begin{abstract}
Writing becomes one of fundamental skills in learning language. In tis digital era, when everything is possible to be done in online, the students prefer to easily find some references in the websites or other online sources. The students hesitate to produce their own ideas in that they can get anything they want on the internet. This cases take a big part of the quality of the students in mastering writing skill. Thus, the teachers should have many alternative to help the students, more to EFL stuents to improve their writing performance through such an online based-learning. Grammarly is one of possible solution can be taken as the students writing assistant while the teachers giving some exercises. The students will be helpful working on Grammarly in that they will be able to produce any languages they know, then Grammarly will take a place to help them correct their work.
\end{abstract}

Keywords: EFL students; online writing assistant; Grammarly

\section{INTRODUCTION}

In this digital era, writing takes a significant role in the EFL students' language acquisition. Meyers (2005) mentions that writing is a matter of the action. In the writing manner, there are some phases, they are the method of finding and arranging the idea, writing and placing it on paper, reshaping and revising the writing. Those are the reasons that categorize writing as one the most complex and complicated language skills (Levy,1995), more for EFL students who have an utterly different background language. EFL teachers are considered the challenging part of teaching practices. Although they are EFL learners, they are generally not inspired or frustrated quickly. All the people claim the foreign language is hard to learn because it varies in many respects from Bahasa Indonesia. In this situation, the teachers should react to the state of the classroom to make it more 
comfortable for the learners. It is being important in that the student have to be qualified in writing skills as the requirements of the school graduation (Ghufron et al., 2016).

Melor \& Salehi (2012) are well recognized during this digitalizing age for coding technology (Automatic Internet application) which can help them learn and study, such as Wike, Twitter, Ms. Word, Grammar software and others. An online learning assistant which is recommended to be used in the EFL writing class is 'Grammarly' (Automatic Internet Programs and Mobile app). It is an electronic database for the proofreading of grammatical texts. It also provides improvements for pronunciation, punctuation, synonyms (use of vocabulary) and the prevention of plagiarism.

Grammarly helps teachers and students correct EFL writing, even though teachers has applied several teaching-online and offline-methods, ways, strategies, or even resources (Daniels \& Leslie, 2013).This is since Grammarly not only can distinguish punctuation (such as missed spaces between periods) and errors in orthographer's spelling, including proper nouns, and provide numerous alternative options for the dispeller's terms. That the teachers are responsible to give such a feedback or correction toward students writing to improve and encourage the quality and accuracy in mastering writing skills, several mistakes dealing with grammatical, structure, spelling, or even the word choices should be highlighted (Wichadee, 2013). The teachers seek to analyze the application of grammar in minimizing mistakes that learners have made in terms of syntax, vocabulary, and semantics (spelling and punctuation), to cope with the above-mentioned problems. When errors are detected, the teacher highlights the paper. Such work will help educators and researchers to recognize and understand how computer software like Grammarly can contribute to the learning of English. For this reason, Fast Company has identified Grammarly as one of the most innovative AI companies in the world.

Besides, it might be possible to better understand how EFL learners, especially in terms of writing, could develop their language skills through online software or even through their own smartphone. With this awareness, researchers and practitioners may build unique, relevant and innovative pedagogical concepts or approaches that use Grammarly effectively for EFL training. Despite the fact that there have been several articles conferring this case, the researchers aim to focus primary on proofing how Grammarly is fully beneficial for EFL students as the assistant helping the teachers to guide the students on writing activities, so this articles will deeply justify on defining 
Grammarly and its features, then how to implement Grammarly in teaching writing in EFL calssroom.

\section{RESEARCH METHOD}

This research implemented descriptive qualititative using library research approach. Qualitative research result data in the form of notes or descriptive data in the online text investigated. The data gathered mainly focused on the origin of Grammarly, features provided by Grammarly, platform connected to Grammarly, Grammar Checker, Plagiarism Checker, and the latest updates of Grammarly features that includes tone detector, mobile synonims, the Grammarly editor, consistency, clarity and readability and premium vs free grammarly. Each data objectively and systematically analyzed and presented descriptively.

\section{RESULTS AND ANALYSIS}

1. The Origin of Grammarly

In 2009, Max Lytvyn, Alex Shevchenko, and Dmytro Lider founded Grammarly to facilitate people a better communication.

Focusing first on supporting students' grammar and spelling through a subscription-based product, they soon saw the potential of how Grammarly could help in all circumstances - from professional writing to everyday correspondence. Over the next ten years, Grammarly grew the capabilities of an AI-powered writing assistant to go way beyond grammar and spelling into complex aspects of language and communication.

Grammarly recently takes a powerful role on facilitating the users to get a better online grammar assisstant by various products offered. Started by developing Grammarly as online web editor, it recently comes on Microsoft add-in, Dekstop app, and amazingly now it is possible to be installed on Mobile keyboards. Thus, Grammarly users increase significantly in last four years up to 20 million daily active users nowadays. 


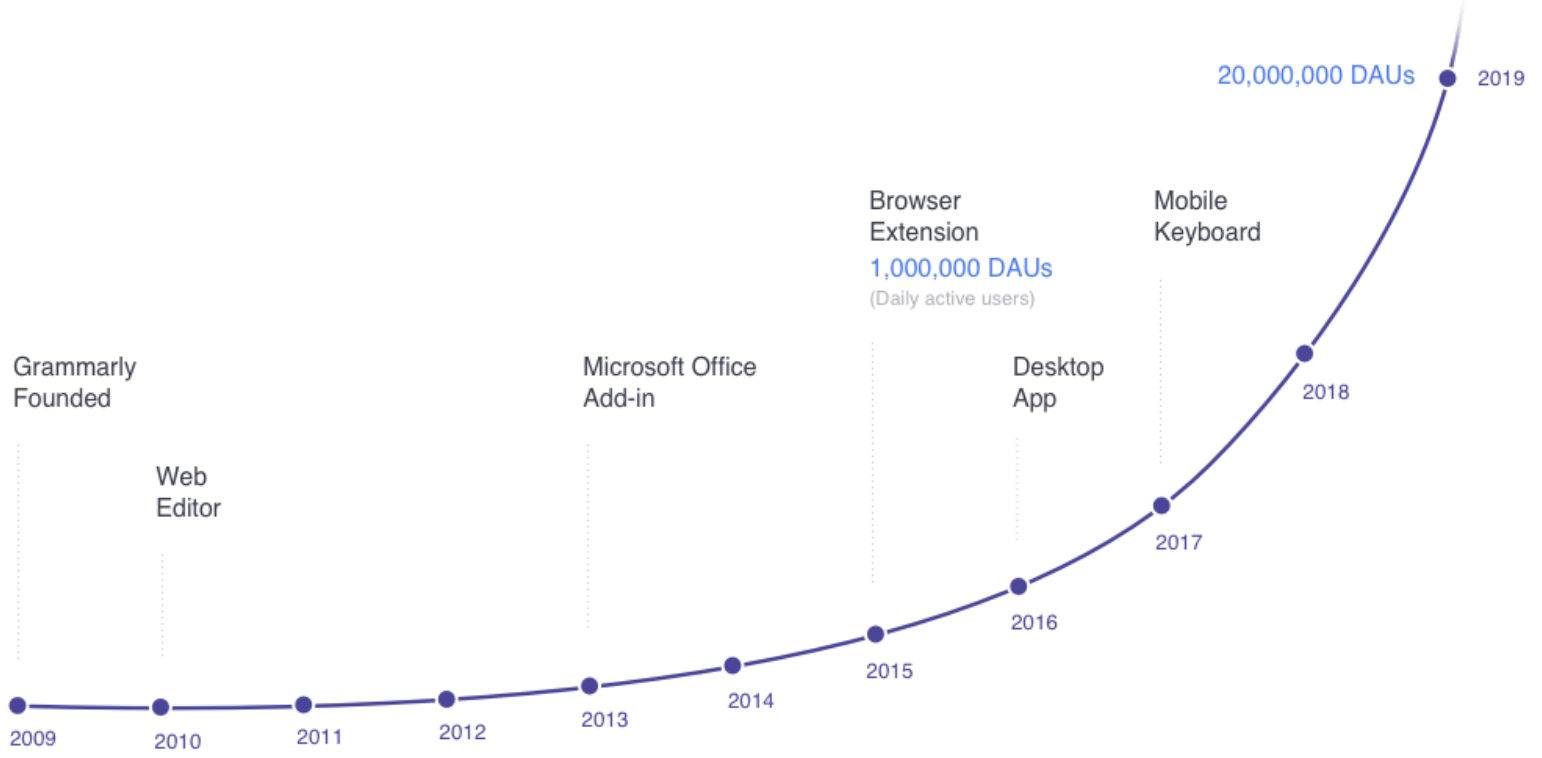

2. Features Provided by Grammarly

2.1. Platform Connected to Grammarly

G grammarly

Get corrections from Grammarly while you write on Gmail,

Twitter, Linkedln, and all your other favorite sites.

Emails and Messages

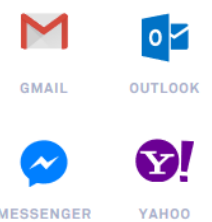

Documents and Projects

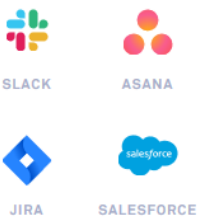

Social Media

$\mathbf{M}$

(1)

$y$ in 


\subsection{Grammar Checker}

Q grammarly

\section{Grammar Check}

Check your English text for grammar, spelling, and

punctuation errors with Grammarly's free grammar checker.
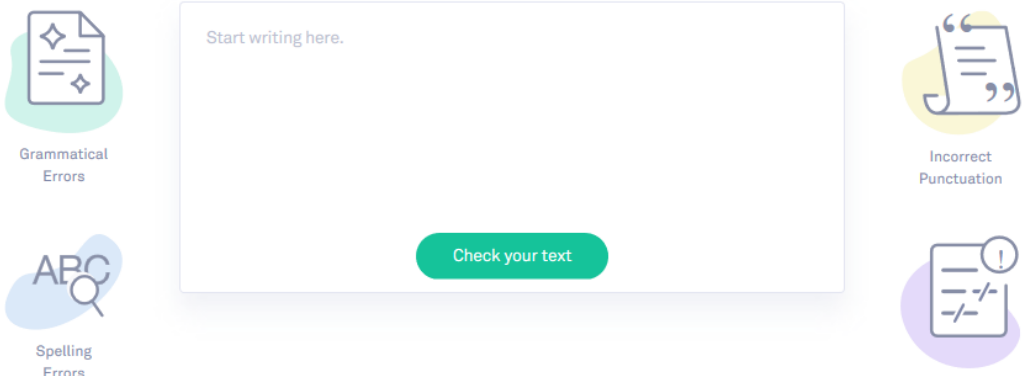

\subsection{Plagiarism Checker}

G grammarly

\section{Plagiarism Checker by Grammarly}

Grammarly's plagiarism checker detects plagiarism

in your text and checks for other writing issues.
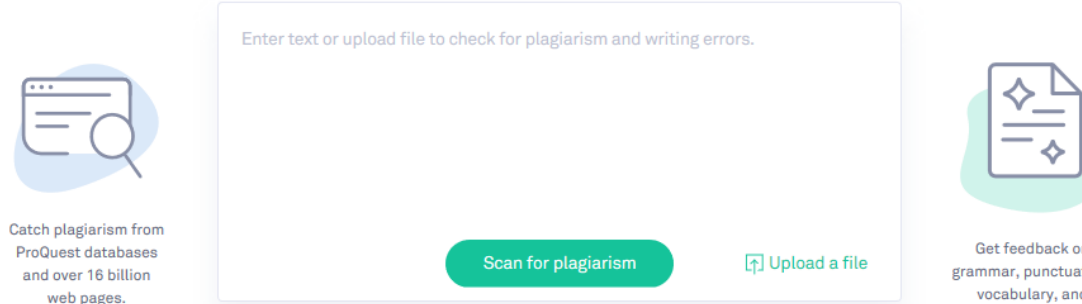

Get feedback on

Geammar, punctuation,

vocabulary, and

sentence structure.

\subsection{Latest Updates of Grammarly Features}

a. Tone Detector

If someone watched an email from a friend to make sure it was not too harsh (or too nice) before he hits send, then he already knows how important it is to express the right tone in his writing. The developers have spent a lot of 2019 building the new tone detector from Grammarly to help the consumers feel confident their tone will come across the way they want it. Through examining word selection, phrasing, punctuation, and even capitalization, Grammarly will tell the consumers whether the message sounds polite, optimistic, worried, or something else altogether. 


\section{Meet Grammarly's tone detector.}

It's not just what you say - it's how you say it. Deliver your message the way you intend to.

\section{Add to Microsoft edge lt's iree}

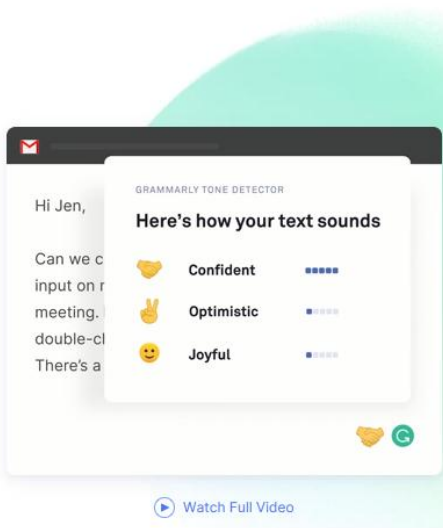

b. Mobile Synonims

To write on your computer always means to write on the go. This means typing fast, even while at the same time doing something else. But that does not mean that someone's prose is sloppy — or bland. Recently, the Grammarly Keyboard offers colorful synonyms for words that someone types on his phone. Just pause for a moment after finishing typing the sentences to see synonyms for a word. Someone can also see synonyms for a word that have typed before by moving the cursor to that word.

\section{c. The Grammarly Editor}

Grammarly's recommendations for writing provide much more than grammar. The Developer updated the Grammarly Editor's look and feel recently to help ensure that someone's work is not only error-free, but also simple, engaging and relevant to the audience and goals.

\section{d. Consistency}

If both OK and okey are appropriate spellings, does it really matter if you use both variants in the same report? It may not be a mistake to switch back and forth, but it may seem a little clumsy to readers. Consistency helps the document look more polished and professional. To help catch inconsistent spelling, hyphenation, capitalization, and more, Grammarly added consistency suggestions to Grammarly Premium. 


\section{e. Clarity and Readability}

Even a perfectly grammatical sentence can be difficult to follow. If it is wordy and overcomplicated, readers may get lost even before they get to the end. Grammarly has updated most of its tips this year that will help the users' writing simple and easy to read.

f. Premium vs Free Grammarly

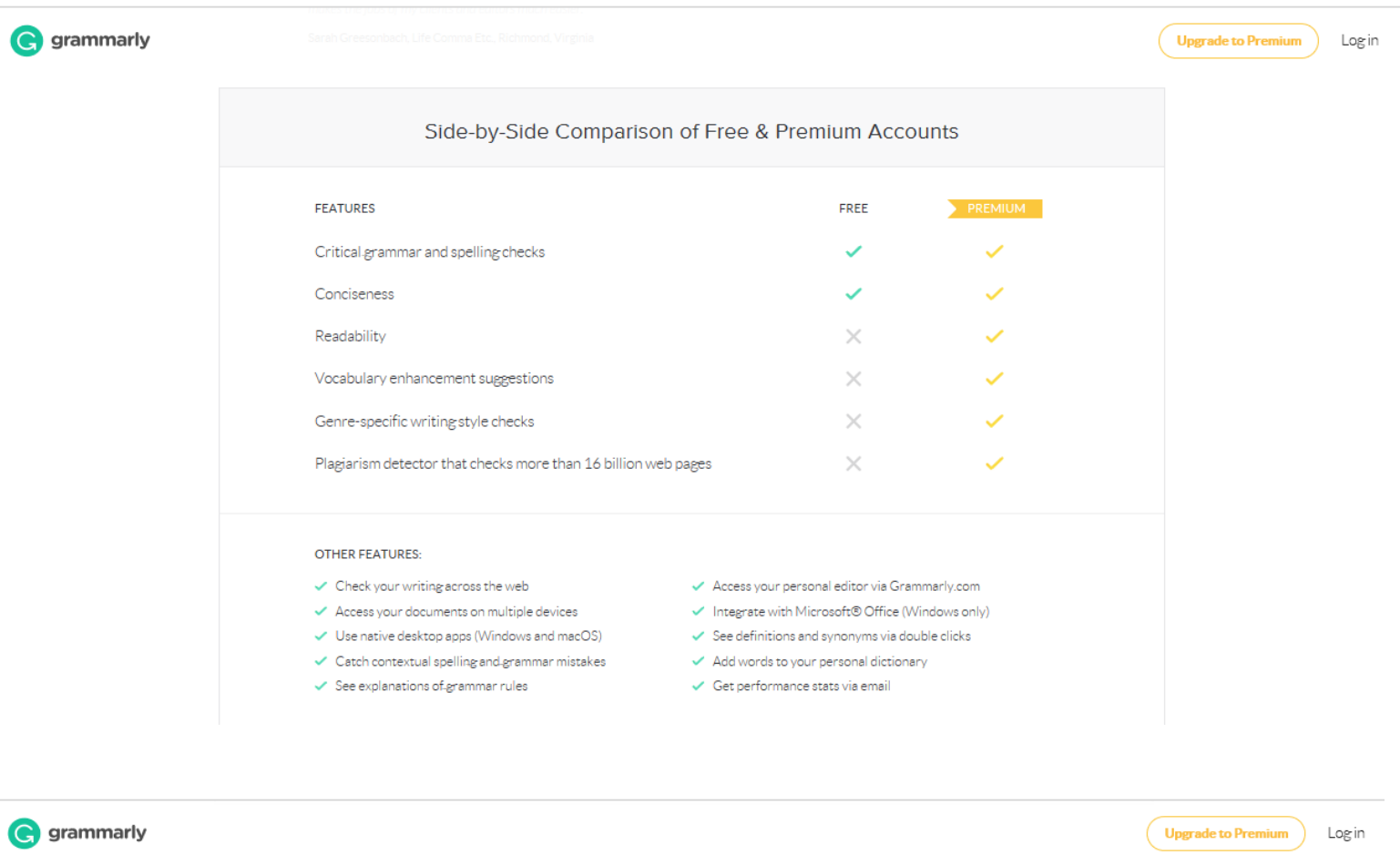

A Deeper Look at Premium-Only Checks

\begin{tabular}{|l|l|l|}
\hline PUNCTUATION & SENTENCE STRUCTURE \\
\hline
\end{tabular}

Future real conditional

Example: If we will leave now, we will arrive early.

will leave $\rightarrow$

The sentence appears to incorrectly phrase the future real

conditional. Consider removing the modal verb will.

The future real conditional includes two clauses and

is used to describe something that will (or likely will)

happen in the future. The verb in the if clause uses the

simple present form. The verb in the other clause uses the

simple future form. Do not use the future modal will in the

if clause. 


\section{A Deeper Look at Premium-Only Checks}

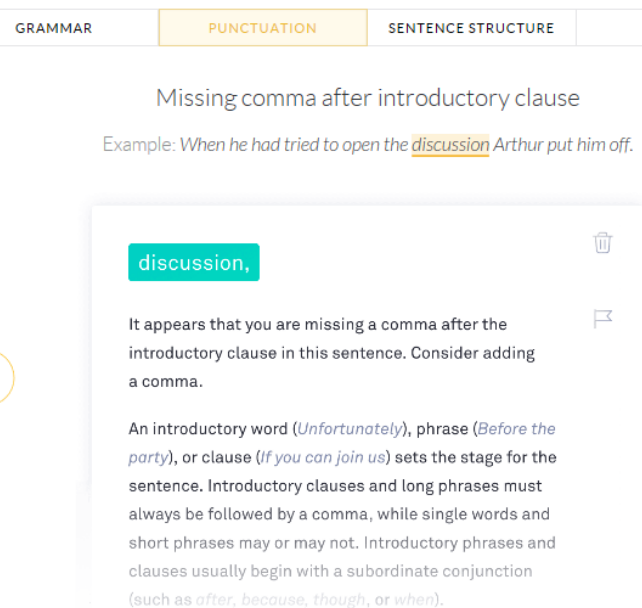

A Deeper Look at Premium-Only Checks

GRAmmAR
Missing verb
He is or He waste
This sentence appears to be missing a verb. Consider
adding a verb or rewriting the sentence.
A complete sentence requires a main clause, which
includes a subject, a verb, and a complete thought. When
one of these components is missing, the result is called
a sentence fragment or incomplete sentence. To correct
the problem, the fragment must be rewritten to include
a main clause or joined in some way with the existing main
clause of another sentence.

4. CONCLUSION

After recognizing the whole aspects provided in Grammarly, the writer tries to sum up those explanations and findings into several specific points can be underlined:

1. Grammarly is an online-based platform which is purposively developed to assist the EFL learners to have a better communication to other people in a simple way producing the language in excellent and enjoyable writing. 
2. Grammarly has perfectly integrated to some of most-used apps or platforms (Gmail, Ms. Office, Facebook, LinkedIn, Slack, etc.) to cover EFL learners' needs to write perfectly in every occasion.

3. Grammarly provides a lot of features which can facilitate the EFL learners to improve their writing skills by freely producing their own words and styles.

However, this article is just the beginning, the writer has limitation to discover more detail and complete information about Grammarly as an online writing assistant for the EFL learners. Therefore, the writer recommends the other researchers to conduct several advanced researches such as doing classroom action research (CAR) or even developing Grammarly as a media in teaching writing for EFL learners. In addition, the writer hopes that this article can be advantageous for all the readers as the students, teachers, or researchers.

\section{ACKNOWLEDGEMENTS}

We thank to Mohammad Zahri, M.Pd. as the Head of STKIP Al Hikmah Surabaya and Achmad Anang Darmawan, M.Pd. as Head of English Department of STKIP Al Hikmah Surabaya for giving such an opportunity to conduct a research. We thank to Ahmad Syafi'I, M.Pd. as the co-author who provide a full time consultation and all students of English Department who joined Academic Writing course.

\section{REFERENCES}

Daniels, P., \& Leslie, D. (2013). Grammar software ready for EFL writers? OnCue Journal, 9(4), 391-401.

Ghufron, M. A., Saleh, M., Sofwan, A., \& Java, E. (2016). A model of research paper writing instructional materials for academic writing course: Needs \& documents analysis and model design. English Language Teaching: Canadian Center of Science and Education, 9(3), 1-12. https://doi.org/10.5539/ elt.v9n3p1.

Grammarly, www.grammarly.com

Levy, C. M. (1995). Is Writing as Difficult as It Seems? Memory and Cognition, 23(6). 
Melor M. Y., \& Salehi, H. (2012). The effectiveness of Facebook groups on teaching and improving writing: Students' perceptions. International Journal of Educational and Information Technologies, 6(1), 87-96. https://doi.org/10.5539/elt.v6n7p1.

Meyers, Allan. 2005. Gateways to Academic Writing: Effective Sentences Paragraph and Essay. New York: Longman.

Wichadee, S. (2013). Peer feedback on Facebook: The use of social networking websites to develop writing ability of undergraduate students. Turkish Online Journal of Distance Education, 14(4), 260-270. https://doi.org/10.17718/TOJDE.25470.

\section{BIOGRAPHIES OF AUTHORS}

N.M.F. Amin Mubarok is English Department of STKIP Al Hikmah Surabaya. His passion is conducting research in incorporating ICT in teaching English particularly teaching writing skill. Ahmad Syafi'I, M.Pd. is a lecturer in English Department of STKIP Al Hikmah Surabaya. His major areas of research are in writing and incorporating ICT in teaching writing. 